\title{
Extreme Learning Machine in Laser-assisted Machining using Waste Palm Cooking Oil
}

\author{
F. YASMIN ${ }^{1}$, K. F. TAMRIN ${ }^{*}, 1$, N. A. SHEIKH ${ }^{2}$ \\ ${ }^{1}$ Department of Mechanical and Manufacturing Engineering, Faculty of Engineering, Universiti Malaysia Sarawak \\ (UNIMAS), 94300 Kota Samarahan, Sarawak, Malaysia \\ ${ }^{2}$ Department of Mechanical Engineering, Faculty of Engineering, International Islamic University, Islamabad, Pakistan \\ *Corresponding author: Email: tkfikri@ unimas.my (K.F.Tamrin) | Tel: +601115653090 | Fax: +6082583410
}

\begin{abstract}
Use of lubricating/cutting fluids is crucial in machining processes to reduce friction, alleviate heat accumulation and prolong tool life. To minimize environmental and health impacts, a number of studies using vegetable oil-based cutting fluid have been investigated and reported demonstrating similar performance obtained using commercial cutting fluids. However, massive use of vegetable oil for such purposes would undeniably trigger issues of food security. In order to mitigate food waste, the primary objective of the chapter is to demonstrate the application of waste palm cooking oil as a potential lubricating fluid in laser-assisted machining of metal. By considering kinematic and dynamic viscosities of the waste cooking oil, its effects on surface roughness and tool wear are studied by predicting using extreme learning machine (ELM). The prediction results show that the average errors are only $0.51 \%$ and $1.19 \%$ for surface roughness and flank wear, respectively, suggesting good agreement between observation and prediction.
\end{abstract}

Keywords: Food waste; machining; lubricant; laser; processing; material; prediction

\section{Introduction}


The lubricants, generally can be classified as automotive and industrial lubricants, are used to improve the life of engines and machines by removing heat [1]. These lubricants, excessively used in industry and transportation, are largely produced as an expensive product of fossil fuel and also contribute significantly to pollution. The replacement of fossil fuels with bio-based oils \& lubricants is not only environment-friendly, owing to biodegradability [2]. One major use of lubricants is in automotive sector in different engine types at varying operating conditions. However, the performance of bio-oils as lubricants have not been much successful as yet owing to tribological issue resulting in deterioration of engine components [1].

While the other use of lubricants in industrial applications are mainly to protect the important operational elements from intensive duty cycles. The most important aspect of such lubricants is their viscosity to retain operations at optimal conditions irrespective of ambient range of working conditions. Bio-oils have been used as machining lubricants which helps in reducing cutting forces along with temperature reduction which can improve tool life. However, one common issue with the mineral based cutting fluids is the production of odour in the vicinity of workplace and higher concentration of fumes can be hazardous for operators. On the other hand, the vegetable-oil based fluid are useful alternative since their bio-degradable nature offers their renewability alongside excellent lubrication properties [2]. A few researchers have developed such cutting fluids. For instance, for turning process, Katna et al. [3] used non-edible neem blended with various percentages (5\%-20\%) of food grade emulsifier and showed promising results in terms of better machined surface finish at $10 \%$ emulsifier blending compared to mineral oil. In addition, the rate of tool wear reduced notably while using neem blended with $5 \%$ emulsifier as cutting fluid in comparison with conventional mineral oil. While using palm oil as cutting fluid during high speed drilling of titanium alloys, Rahim and Sasahara [4] observed lower cutting forces and resultantly lesser temperature of workpieces compared to the use of synthetic ester as cutting fluid. Wickramasinghe et al. [5] used a novel coconut-oil based while performing end milling operation on 
samples made of AISI 304 steel. Results indicated that around 70\% reduction in average surface roughness along with $48 \%$ reduction in flank wear in comparison with soluble oil as working fluid. In addition, Bermingham et al. [6] used laser-assisted milling of Ti-6Al-4V with vegetable-based cutting fluid to evaluate the life of tool and the wear mechanism. The results suggested that the tool life improved around five times with respect to conventional dry laser-assisted milling. Such studies are underway with some hick-ups and limitations [7, 8]. Nevertheless, massive use of bio-oils extracted from edible crops such as palm and soybean has raised serious concerns on food insecurity.

On the other hand, wasting food is becoming a social problem along with its ecological and economic impacts. Globally around a quarter more than a billion ton of food is either lost or wasted [9]. Estimates of 2012 for Malaysia suggested that around 33 thousand tonnes of food is daily wasted and this amount is on further rise owing to urbanization, changes in lifestyle, population growth and industrialization. Large chunk of food wastes especially of organic origin is generated from common households, restaurants and other industries in the food processing industries [10]. One peculiar item as waste, in millions of tons per day, is the cooking oil. Converting waste cooking oil of houses, restaurants etc. to lubricants can help address one major environmental challenge since its disposal is a grave concern for countries across the globe [11]. To the best of authors' knowledge, no investigation has been performed on metal machining using waste cooking oil as industrial lubricant except automotive lubricants.

Different waste cooking oil would produce different machining characteristics and tribological properties. Characterization of waste cooking oil is necessary but laboriously time consuming due to varying external factors. However, predicting the behavior of cooking oil in different engines and working environments is not an easy task. One important aspect is the use of prediction models especially at the planning stage to assess the behavior of tribological applications in finding suitable 
parametric ranges for better performance [12-14]. This approach can mitigate the assessment process complexities with lesser rejections and errors. With the benefits of artificial intelligence (AI), as noted in many fields including manufacturing processes, different variants such as Artificial Neural Network (ANN), genetic algorithm, fuzzy logic etc. can be efficiently used to model the process. One critical aspect of these techniques is the time consumption during learning process in addition to generalization and overfitting [15]. For instance, ANN requires a certain set of data for generalization while over training can lead to overfitting [16]. One alternate is the extreme learning machine (ELM) which uses weights for the hidden nodes [17]. In addition, ELM is relatively simplified than ANN, while it reduces the time for train-test, moreover it also provides better generalization in case of overfitting issues. In this regard, the comparison carried out by Mustafa [18] between ANN model and ELM indicated that the ELM estimates are superior than its counterpart along with fast learning at lesser number of iterations. Similarly, the work by Anicic et al. [19] demonstrated the same predictions. In general, ELM demonstrate high capabilities in all three areas of learning speeds, training errors and norms of weights compared to other algorithms such as back-propagation [20].

Keeping in view the relevant literature in terms of exploring innovative methods and practices for mitigating food wastages, this chapter analyzed the effect of waste palm cooking oil on surface roughness of $6082 \mathrm{Al}$ alloy and tool's flank wear width by predicting using ELM. Here, kinematic and dynamic viscosities of the waste cooking oil were also estimated as input parameters for machining. The methodology is described in the following section.

\section{Methodology}

\subsection{Experimental details}


In this chapter, a medium strength aluminum alloy (6082) having $6 \mathrm{~mm}$ thickness was used while undergoing laser-assisted high speed milling. The selected material is corrosion resistant with melting point of $555^{\circ} \mathrm{C}$, thermal conductivity of $180 \mathrm{~W} / \mathrm{m} . \mathrm{K}$ and Hardness Brinell (HB) of 91 . A detailed chemical composition of the selected material can be found in [21].

The setup for high speed milling operation included a cutting system along with lubricant fluid delivered in droplets and a heating system operating continuously by using laser power as shown in Fig. 1. The heating system is positioned as top laser-heating which is preferred during radial cutting owing to wider heating area; while the side heating position is efficient during axial cutting [22]. Here side laser-heating method is more preferable rather than top laser-heating method. The machine with numerical control for milling was X-Carve having maximum speed of $8000 \mathrm{~mm} / \mathrm{min}$ with in the plane while in the out of plane direction (z-axis) a maximum of $500 \mathrm{~mm} / \mathrm{min}$ speed can be achieved. A 4-flute micro grain carbide end-mill tool was used having $3.175 \mathrm{~mm}$ diameter and coated with aluminum titanium nitride (AlTiN).

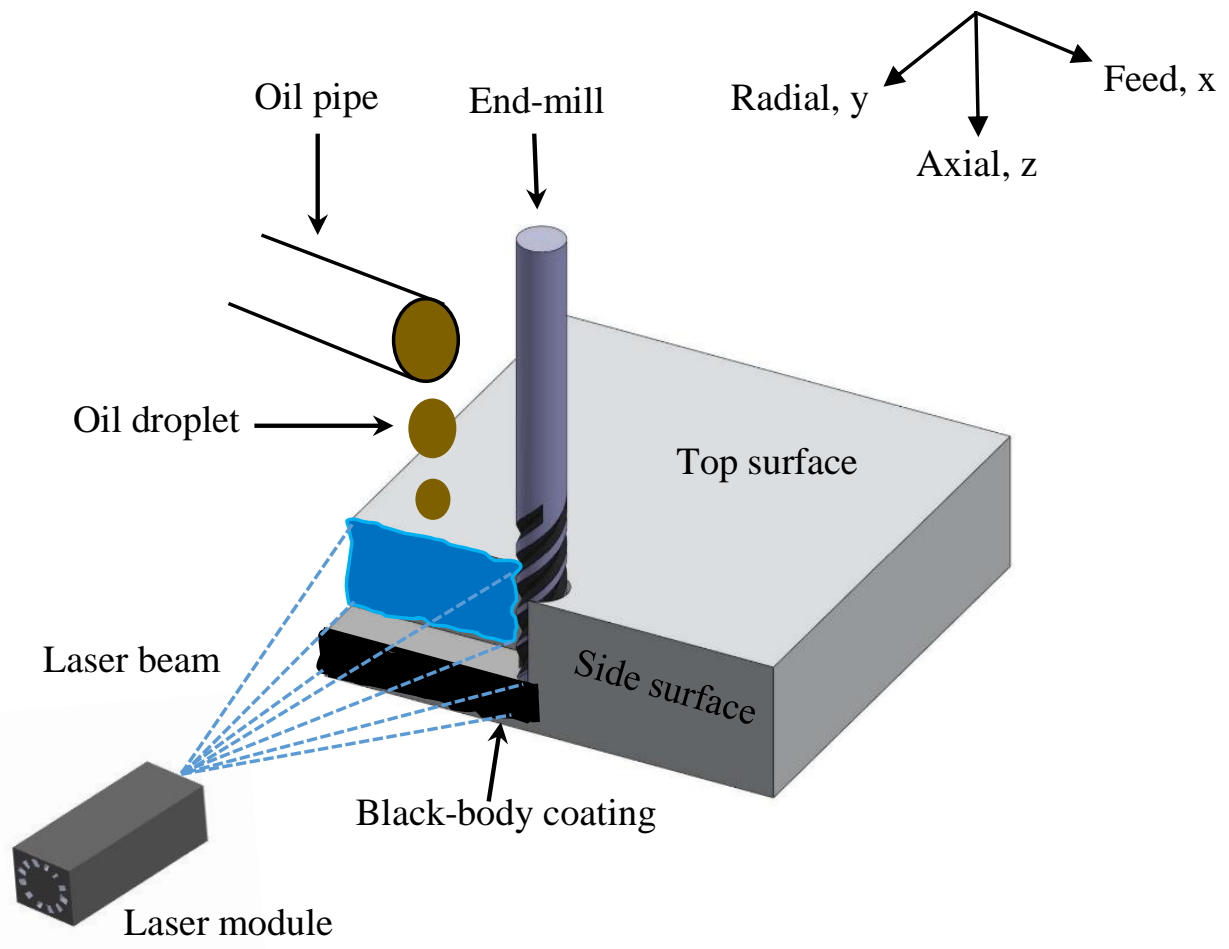


Fig. 1. Schematic diagram of the experimental setup

The continual side heating source was a diode laser having $1.6 \mathrm{~W}$ power at wavelength of 445 $\mathrm{nm}$. The used beam spot of the laser had spot size of $20 \times 6 \mathrm{~mm}^{2}$, approximately equivalent to cutting area. To enhance absorptivity of radiations at the substrate alloy, the cutting zone was coated with blackbody coating. Before initialization of cutting process, the substrate was pre-heated for at least 2 minutes.

In this chapter, waste or used sample of Malaysian palm cooking oil was explored as lubricating fluid during machining. The physio-chemical properties are given in Table 1 for both off-the-shelf and waste palm cooking oil [23].

Table 1: Physiochemical properties of bought and waste palm cooking oil [23]

\begin{tabular}{|l|c|c|}
\hline \multicolumn{1}{|c|}{ Properties } & $\begin{array}{c}\text { Off-the-shelf palm } \\
\text { cooking oil }\end{array}$ & Waste palm cooking oil \\
\hline Acid value $(\mathrm{mg} \mathrm{KOH} / \mathrm{gm})$ & 0.3 & 4.03 \\
\hline Calorific value $(\mathrm{J} / \mathrm{gm})$ & ------ & 39658 \\
\hline Saponification value $(\mathrm{mg} \mathrm{KOH} / \mathrm{gm})$ & 194 & 177.97 \\
\hline Peroxide value $(\mathrm{meq} / \mathrm{kg})$ & $<10$ & 10 \\
\hline Density $\left(\mathrm{gm} / \mathrm{cm}^{3}\right)$ & 0.898 & 44.956 \\
\hline Kinematic Viscosity $\left(\mathrm{mm}^{2} / \mathrm{s}\right)$ & 39.994 & 40.519 \\
\hline Dynamic Viscosity $(\mathrm{mpa} . \mathrm{s})$ & 35.920 & $222-224$ \\
\hline Flash point $\left({ }^{\circ} \mathrm{C}\right)$ & $161-164$ & 0.140 \\
\hline Moisture content $(\mathrm{wt} \%)$ & 0.101 & \\
\hline
\end{tabular}

\subsection{Design of Experiments}

The design of experiments was carried out for three important parameters involved in the machining process namely, feed rate of cutting, lubricant flow rate and the used laser power. In order to practice the process, several dry runs of the apparatus indicated the ranges of the selected parameters in terms of their results in producing the finished surface and the wear of the tool. At high speed milling 
of Al 6082, feed rate range between $1500-3500 \mathrm{~mm} / \mathrm{min}$ was selected with acceptable machined surface finish. In similar fashion ranges for laser power was selected between $650 \mathrm{~mW}-850 \mathrm{~mW}$ while the ranges of cutting fluid kinematic viscosities are tabulated in Table 2 [23]. The quantity of cutting fluid was kept between 0.15 to $0.25 \mathrm{~mL} / \mathrm{s}$ at pump voltage of $6.8 \mathrm{~V}$ to $8.3 \mathrm{~V}$.

Table 2: Kinematic and dynamic viscosity of palm cooking oil

\begin{tabular}{|c|c|c|c|c|c|c|}
\hline \multicolumn{3}{|c|}{ Input parameter } & \multicolumn{4}{|c|}{ Fluid characteristics } \\
\hline \multirow[b]{2}{*}{ No. } & \multirow[b]{2}{*}{$\begin{array}{l}\text { Power } \\
(\mathrm{mW})\end{array}$} & \multirow{2}{*}{$\begin{array}{l}\text { Predicted } \\
\text { temperature } \\
\text { rise }\left({ }^{\circ} \mathrm{C}\right)\end{array}$} & \multicolumn{2}{|c|}{$\begin{array}{l}\text { Off-the-shelf palm } \\
\text { cooking oil }\end{array}$} & \multicolumn{2}{|c|}{ Waste palm cooking oil } \\
\hline & & & $\begin{array}{c}\text { Kinematic } \\
\text { viscosity } \\
\left(\mathrm{mm}^{2} / \mathrm{s}\right)\end{array}$ & $\begin{array}{c}\text { Dynamic } \\
\text { viscosity } \\
(\mathrm{mPa} . \mathrm{s})\end{array}$ & $\begin{array}{c}\text { Kinematic } \\
\text { viscosity } \\
\left(\mathrm{mm}^{2} / \mathrm{s}\right)\end{array}$ & $\begin{array}{c}\text { Dynamic } \\
\text { viscosity } \\
(\mathrm{mPa} . \mathrm{s})\end{array}$ \\
\hline 1 & 0 at $40^{\circ} \mathrm{C}$ & 0 & 39.994 & 35.920 & 44.956 & 40.519 \\
\hline 2 & 650 & 32.37 & 58.81 & 51.42 & 63.77 & 59.33 \\
\hline 3 & 750 & 33.5 & 55.38 & 48.24 & 60.34 & 55.90 \\
\hline 4 & 850 & 34.64 & 52.05 & 45.36 & 57.01 & 52.57 \\
\hline
\end{tabular}

Using CCD (Central Composite Design), the design of experiments was prepared with high and low levels of process parameters at setpoints of high (+1), central point $(0)$ and low $(-1)$. The resultant levels generate six axial points along with six central points with one replicate as summarized in Table 3, resulting in 20 experiments.

Table 3: Input processing parameters based on CCD

\begin{tabular}{|c|c|c|c|c|c|}
\cline { 3 - 6 } \multicolumn{2}{c|}{} & \multicolumn{3}{c|}{ Extension } \\
\hline Parameter & Unit & Annotation & -1 & 0 & +1 \\
\hline Feed rate & $\mathrm{mm} / \mathrm{min}$ & $F$ & 1500 & 2500 & 3500 \\
\hline Laser Power & $\mathrm{mW}$ & $P$ & 650 & 750 & 850 \\
\hline Droplet flow rate & $\mathrm{mL} / \mathrm{s}$ & $r$ & 0.15 & 0.2 & 0.25 \\
\hline Kinematic viscosity & $\mathrm{mm} / \mathrm{s}$ & $v_{k}$ & 63.77 & 60.34 & 57.01 \\
\hline Dynamic viscosity & $\mathrm{mPa} . \mathrm{s}$ & $v_{d}$ & 59.33 & 55.90 & 52.57 \\
\hline
\end{tabular}




\subsection{Extreme Learning Machine (ELM)}

In order to deduce conclusive evidence from the experimental setup and runs, a learning algorithm is employed. In this regard, ELM provides the linear and easy to implement learning machine as proposed by Huang et al. [17]. ELM improves the ability for generalization of feed forward ANN by applying the learning structure to the hidden-layered.

In addition, the output weights are selected using Moore-Penrose generalized inverse in ELM while the initial guess of the weights as well as biases can be still arbitrary. The network training requirements are not necessarily present as linear equality, and is solved in a single step which significantly reducing the time for relating $N$ number of input with output (input $x_{N}$ and output $y_{N}$ ) vectors.

The goal here is to relate the input process parameters with the output of the machining, as identified earlier, in the complete set of experiments. For instance, in an $i^{\text {th }}$ training of ELM, inputs $x_{j}$ are used to relate to responses $y_{j}$ with $j=1,2, \ldots, M$. Here $M$ represents the total number of hidden layers defined as,

$y_{j}=\sum_{j=1}^{M} \beta_{j} f\left(x_{j}, w_{j}, b_{j}\right)$

where $\beta_{j}$ are the weights of the output layer while $f$ represents the activation function. $w_{j}$ representing the weight vector connects the $j^{\text {th }}$ node of hidden and input with $b_{j}$ representing the bias of hidden nodes. Upon further simplifications, in the form of $\mathrm{H}$ the final equation is expressed by Eq. (3),

$$
\begin{aligned}
& H=\left[\begin{array}{ccc}
f\left(x_{1}, w_{1}, b_{1}\right) & \ldots & f\left(x_{1}, w_{M}, b_{M}\right) \\
\vdots & \ldots & \vdots \\
f\left(x_{N}, w_{1}, b_{1}\right) & \ldots & f\left(x_{N}, W_{M}, b_{M}\right)
\end{array}\right] \\
& Y=H \beta
\end{aligned}
$$


While the criteria for ELM is as follows,

$L(X, Y ; \beta)=\|Y-H \beta\|^{2}$

Since ELM, unlike ANN, can seek output with the need for iterative procedure [24]; therefore the value for $\beta$ can be found using,

$\beta=H^{+} Y$

The Moore-Penrose inverse of unique matrix $H$ is represented by $H^{+}$also known as generalized inverse matrix.

In this chapter, using ELM the relationship between inputs (process parameters) and outputs (surface roughness and flank wear) are built based on the above mentioned data. The training data is categorized as 14 input sets/samples randomly selected from the total 20 data points while the rest six datasets were used to test data. Moreover, both inputs as well as outputs were initially normalized on a scale of -1.0 to 1.0 at the start of network training. Using MATLAB R2016a, ELM relied on a single user-defined value representing the number of hidden nodes which was varied between 1 to 12 , less than total number of test samples [25]. While for the activation function, sigmoidal function was used.

\section{Results and Discussion}

After conducting the planned set of experimentations, each of the designated response variables were measured and examined which are listed in Table 4.

Table 4. Experimental cases and results using waste palm cooking oil 


\begin{tabular}{|c|c|c|c|c|c|c|c|}
\hline No. & $\begin{array}{c}\text { Feed } \\
\text { rate } \\
(\mathrm{mm} / \\
\mathrm{min})\end{array}$ & $\begin{array}{c}\text { Power } \\
(\mathrm{mW})\end{array}$ & $\begin{array}{c}\text { Flow } \\
\text { rate } \\
(\mathrm{mL} / \mathrm{s})\end{array}$ & $\begin{array}{c}\text { Kinematic } \\
\text { viscosity } \\
\left(\mathrm{mm}^{2} / \mathrm{s}\right)\end{array}$ & $\begin{array}{c}\text { Dynamic } \\
\text { viscosity } \\
(\mathrm{mPa} . \mathrm{s})\end{array}$ & $\begin{array}{c}\text { Flank } \\
\text { wear }(\mu \mathrm{m})\end{array}$ & $\begin{array}{c}\text { Surface } \\
\text { roughness }(\mu \mathrm{m})\end{array}$ \\
\hline 1 & 1500 & 650 & 0.15 & 63.77 & 59.33 & 1.98 & 1.529 \\
\hline 2 & 1500 & 850 & 0.25 & 57.01 & 52.57 & 1.70 & 1.499 \\
\hline 3 & 3500 & 650 & 0.15 & 63.77 & 59.33 & 2.46 & 1.648 \\
\hline 4 & 3500 & 850 & 0.25 & 57.01 & 52.57 & 2.02 & 1.612 \\
\hline 5 & 1500 & 750 & 0.20 & 60.34 & 55.90 & 1.88 & 1.521 \\
\hline 6 & 3500 & 750 & 0.20 & 60.34 & 55.90 & 2.25 & 1.627 \\
\hline 7 & 1500 & 650 & 0.25 & 63.77 & 59.33 & 1.90 & 1.526 \\
\hline 8 & 2500 & 650 & 0.20 & 63.77 & 59.33 & 2.04 & 1.546 \\
\hline 9 & 3500 & 850 & 0.15 & 57.01 & 52.57 & 2.13 & 1.622 \\
\hline 10 & 1500 & 850 & 0.15 & 57.01 & 52.57 & 1.77 & 1.513 \\
\hline 11 & 2500 & 850 & 0.20 & 57.01 & 52.57 & 1.86 & 1.552 \\
\hline 12 & 3500 & 650 & 0.25 & 63.77 & 59.33 & 2.34 & 1.631 \\
\hline 13 & 2500 & 750 & 0.15 & 60.34 & 55.90 & 2.02 & 1.542 \\
\hline 14 & 2500 & 750 & 0.25 & 60.34 & 55.90 & 1.88 & 1.541 \\
\hline 15 & 2500 & 750 & 0.20 & 60.34 & 55.90 & 1.97 & 1.534 \\
\hline 16 & 2500 & 750 & 0.20 & 60.34 & 55.90 & 1.95 & 1.541 \\
\hline 17 & 2500 & 750 & 0.20 & 60.34 & 55.90 & 1.94 & 1.538 \\
\hline 18 & 2500 & 750 & 0.20 & 60.34 & 55.90 & 1.97 & 1.544 \\
\hline 19 & 2500 & 750 & 0.20 & 60.34 & 55.90 & 1.96 & 1.550 \\
\hline 20 & 2500 & 750 & 0.20 & 60.34 & 55.90 & 1.94 & 1.536 \\
\hline
\end{tabular}

\subsection{Prediction using Extreme Learning Machine (ELM)}

Predictions using ELM for the surface roughness and flank wear using waste palm cooking oil, are shown in Table 5 and Table 6, respectively. The hidden nodes were used for the prediction of surface roughness and flank wear having the smallest norm of the least-squares solution. In this case, the root mean square errors are minimum at 4 and 8 number hidden nodes for surface roughness and flank wear, respectively, where the average errors are only $0.51 \%$ and $1.19 \%$ suggesting that the observation are in fine agreement with predictions.

Table 5: ELM prediction of surface roughness using waste palm cooking oil 


\begin{tabular}{|c|c|c|c|c|c|c|c|c|}
\hline \multicolumn{6}{|c|}{ Input parameter } & \multirow{2}{*}{\multicolumn{3}{|c|}{$\begin{array}{c}\text { Machining characteristics } \\
\text { Surface roughness }(\mathrm{Ra})\end{array}$}} \\
\hline \multirow[b]{2}{*}{ Run } & \multirow{2}{*}{$\begin{array}{c}\text { Feed } \\
\text { rate } \\
(\mathrm{mm} / \\
\mathrm{min})\end{array}$} & \multirow[b]{2}{*}{$\begin{array}{l}\text { Power } \\
(\mathrm{mW})\end{array}$} & \multirow{2}{*}{$\begin{array}{l}\text { Flow } \\
\text { rate } \\
(\mathrm{mL} / \mathrm{s})\end{array}$} & \multirow{2}{*}{$\begin{array}{c}\text { Kinematic } \\
\text { viscosity } \\
\left(\mathrm{mm}^{2} / \mathrm{s}\right)\end{array}$} & \multirow{2}{*}{$\begin{array}{c}\text { Dynamic } \\
\text { viscosity } \\
\text { (mPa.s) }\end{array}$} & & & \\
\hline & & & & & & $\begin{array}{l}\text { Experimentation } \\
\qquad(\mu \mathrm{m})\end{array}$ & $\begin{array}{l}\text { Prediction } \\
\quad(\mu \mathrm{m})\end{array}$ & $\begin{array}{c}\text { Error } \\
\%\end{array}$ \\
\hline 1 & 2500 & 850 & 0.2 & 57.01 & 52.57 & 1.552 & 1.5321 & 1.28 \\
\hline 2 & 3500 & 850 & 0.25 & 57.01 & 52.57 & 1.612 & 1.6191 & 0.44 \\
\hline 3 & 1500 & 750 & 0.2 & 60.34 & 55.9 & 1.521 & 1.5166 & 0.29 \\
\hline 4 & 3500 & 650 & 0.15 & 63.77 & 59.33 & 1.648 & 1.6343 & 0.83 \\
\hline 5 & 1500 & 650 & 0.25 & 63.77 & 59.33 & 1.526 & 1.5248 & 0.08 \\
\hline 6 & 2500 & 750 & 0.15 & 60.34 & 55.9 & 1.542 & 1.5402 & 0.12 \\
\hline & & & & & & Average el & or $\%$ & 0.51 \\
\hline
\end{tabular}

Table 6: ELM prediction of flank wear using waste palm cooking oil

\begin{tabular}{|c|c|c|c|c|c|c|c|c|}
\hline \multicolumn{7}{|c|}{ Input parameter } & \multicolumn{3}{|c|}{ Machining characteristics } \\
\hline Run & $\begin{array}{c}\text { Feed } \\
\text { rate } \\
(\mathrm{mm} / \\
\mathrm{min})\end{array}$ & $\begin{array}{c}\text { Power } \\
(\mathrm{mW})\end{array}$ & $\begin{array}{c}\text { Flow } \\
\text { rate } \\
(\mathrm{mL} / \mathrm{s})\end{array}$ & $\begin{array}{c}\text { Kinematic } \\
\text { viscosity } \\
\left(\mathrm{mm}^{2} / \mathrm{s}\right)\end{array}$ & $\begin{array}{c}\text { Dynamic } \\
\text { viscosity } \\
(\mathrm{mPa} . \mathrm{s})\end{array}$ & $\begin{array}{c}\text { Flank wear }(\mathrm{VB}) \\
(\mu \mathrm{m})\end{array}$ & $\begin{array}{c}\text { Experimentation } \\
(\mu \mathrm{m})\end{array}$ & $\begin{array}{c}\text { Prediction } \\
\%\end{array}$ \\
\hline 1 & 2500 & 850 & 0.2 & 57.01 & 52.57 & 1.86 & 1.8515 & 0.46 \\
\hline 2 & 3500 & 850 & 0.25 & 57.01 & 52.57 & 2.02 & 2.0306 & 0.52 \\
\hline 3 & 1500 & 750 & 0.2 & 60.34 & 55.9 & 1.88 & 1.8117 & 3.63 \\
\hline 4 & 3500 & 650 & 0.15 & 63.77 & 59.33 & 2.46 & 2.4387 & 0.87 \\
\hline 5 & 1500 & 650 & 0.25 & 63.77 & 59.33 & 1.90 & 1.8875 & 0.66 \\
\hline 6 & 2500 & 750 & 0.15 & 60.34 & 55.9 & 2.02 & 1.9996 & 1.01 \\
\hline
\end{tabular}

\section{Conclusions}

In this chapter, using ELM, the prediction of waste palm cooking oil as cutting fluid on laser-assisted milling operation of Aluminum alloy is carried out in terms of assessment of surface roughness and flank wear. Some important points can be drawn as conclusion from this work as follows: 
1) The environmental concern on the impact of mineral oil/lubricants and their life cycle are significant and many researchers are trying to develop alternates using possibly renewable and lesser harmful vegetable oils for such purposes.

2) In the current chapter, the use of waste cooking oil in terms of its potential as alternative cutting fluid/lubricant in metal machining process was presented. The results show promising aspect from the view point of viscosity of such oil as lubricant.

3) ELM-based prediction errors of the surface roughness and flank wear were only $0.51 \%$ and $1.19 \%$, respectively using waste palm cooking oil, suggesting good agreement between observations and predictions.

\section{Acknowledgments}

The authors are grateful to Universiti Malaysia Sarawak for the Grant no. F02/TOC/1750/2018 allocated to the project.

\section{References}

1. J. Alotaibi and B. Yousif, Biolubricants and the potential of waste cooking oil, in Ecotribology. 2016, Springer. p. 125-143.

2. S. Debnath, M.M. Reddy, and Q.S. Yi, Environmental friendly cutting fluids and cooling techniques in machining: a review. J. Cleaner Prod., 2014. 83: p. 33-47.

3. R. Katna, K. Singh, N. Agrawal, and S. Jain, Green manufacturing-performance of a biodegradable cutting fluid. Mater Manuf Process, 2017. 32(13): p. 1522-1527.

4. E. Rahim and H. Sasahara, A study of the effect of palm oil as MQL lubricant on high speed drilling of titanium alloys. Tribology Int, 2011. 44(3): p. 309-317.

5. K. Wickramasinghe, G. Perera, and H. Herath, Formulation and performance evaluation of a novel coconut oil-based metalworking fluid. Mater Manuf Process, 2017. 32(9): p. 1026-1033.

6. M. Bermingham, W. Sim, D. Kent, S. Gardiner, and M. Dargusch, Tool life and wear mechanisms in laser assisted milling Ti-6Al-4V. Wear, 2015. 322: p. 151-163.

7. Y. Luo, L. Yang, and M. Tian, Influence of bio-lubricants on the tribological properties of Ti6Al4V alloy. Journal of Bionic Engineering, 2013. 10(1): p. 84-89.

8. R. Kreivaitis, M. Gumbyte, K. Kazancev, J. Padgurskas, and V. Makarevičienè, A comparison of pure and natural antioxidant modified rapeseed oil storage properties. Industrial Crops and Products, 2013. 43: p. 511-516.

9. C. Martin-Rios, C. Demen-Meier, S. Gössling, and C. Cornuz, Food waste management innovations in the foodservice industry. Waste management, 2018. 79: p. 196-206.

10. H.S. Hafid, A.R. Nor'Aini, M.N. Mokhtar, A.T. Talib, A.S. Baharuddin, and M.S.U. Kalsom, Over production of fermentable sugar for bioethanol production from carbohydrate-rich Malaysian food waste via sequential acid-enzymatic hydrolysis pretreatment. Waste Management, 2017. 67: p. 95-105. 
11. H.S. Ng, P.E. Kee, H.S. Yim, P.-T. Chen, Y.-H. Wei, and J.C.-W. Lan, Recent advances on the sustainable approaches for conversion and reutilization of food wastes to valuable bioproducts. Bioresource technology, 2020. 302: p. 1-37.

12. K. Tamrin, S. Zakariyah, and N. Sheikh, Multi-criteria optimization in CO2 laser ablation of multimode polymer waveguides. Optics and Lasers in Engineering, 2015. 75: p. 48-56.

13. K. Tamrin and A. Zahrim, Determination of optimum polymeric coagulant in palm oil mill effluent coagulation using multiple-objective optimisation on the basis of ratio analysis (MOORA). Environmental Science and Pollution Research, 2017. 24(19): p. 15863-15869.

14. K. Tamrin, S. Zakariyah, K. Hossain, and N. Sheikh, Experiment and prediction of ablation depth in excimer laser micromachining of optical polymer waveguides. Advances in Materials Science and Engineering, 2018. vol. 2018: p. 1-9.

15. N. Ahmad and T.V. Janahiraman, Modelling and prediction of surface roughness and power consumption using parallel extreme learning machine based particle swarm optimization, in Proc ELM2014 Vol 2. 2015, Springer. p. 321-329.

16. M. Dashtbayazi, Artificial neural network-based multiobjective optimization of mechanical alloying process for synthesizing of metal matrix nanocomposite powder. Mater Manuf Process, 2012. 27(1): p. $33-42$.

17. G.-B. Huang, Q.-Y. Zhu, and C.-K. Siew, Extreme learning machine: theory and applications. Neurocomputing, 2006. 70(1-3): p. 489-501.

18. A. Mustafa, Modelling of the hole quality characteristics by Extreme Learning Machine in fiber laser drilling of Ti-6Al-4V. J Manuf Process, 2018. 36: p. 138-148.

19. O. Anicic, S. Jović, H. Skrijelj, and B. Nedić, Prediction of laser cutting heat affected zone by extreme learning machine. Optics Lasers Eng., 2017. 88: p. 1-4.

20. Ž. Ćojbašić, D. Petković, S. Shamshirband, C.W. Tong, S. Ch, P. Janković, N. Dučić, and J. Baralić, Surface roughness prediction by extreme learning machine constructed with abrasive water jet. Precis. Eng., 2016. 43: p. 86-92.

21. G. Quintana, X. Gomez, J. Delgado, and J. Ciurana, Influence of cutting parameters on cycle time, surface roughness, dimensional error and cutting forces in milling operations on aluminium 6082 sculptured surface geometry. Int J Machining Machinability Mater, 2010. 8(3-4): p. 339-355.

22. H. Ding, N. Shen, and Y.C. Shin, Thermal and mechanical modeling analysis of laser-assisted micromilling of difficult-to-machine alloys. J Mater Process Tech, 2012. 212(3): p. 601-613.

23. Z. Ullah, M.A. Bustam, and Z. Man, Characterization of waste palm cooking oil for biodiesel production. International Journal of Chemical Engineering and Applications, 2014. 5(2): p. 134-137.

24. F. Ucar, O. Alcin, B. Dandil, and F. Ata, Power quality event detection using a fast extreme learning machine. Energies, 2018. 11(1): p. 1-14.

25. G. Feng, G.-B. Huang, Q. Lin, and R. Gay, Error minimized extreme learning machine with growth of hidden nodes and incremental learning. IEEE Trans. Neural Netw, 2009. 20(8): p. 1352-1357. 